\title{
Response to Letter to the Editor, "Dentin Bonding Testing Using a Mini-interfacial Fracture Toughness Approach"
}

Journal of Dental Research

(C) International \& American Associations for Dental Research 2016

Reprints and permissions: sagepub.com/journalsPermissions.nav DOI: |0.I| $77 / 00220345$ I6652/27 jdr.sagepub.com

\section{P. Pongprueksa',2, J. De Munck', K. Karunratanakul', B.C. Barreto', A. Van Ende', P. Senawongse ${ }^{2}$, and B. Van Meerbeek'}

In response to the letter to the editor by Ruse (2016), we confirm that the finite element modeling dimensions were similar to those of the actually tested specimens; the depicted model in Figure 1 is shorter in order to detail the loaded part. During initial loading, stress was not entirely uniformly distributed but concentrated at the actual adhesive-dentin interface (Appendix Fig. 1c, d). Once the crack propagated, stress uniformly distributed (Appendix Fig. 1e, f). Scanning electron microscopy confirmed a parallel crack progression, also witnessed by the observed hackle. We assume that nonuniform stress distribution would have led to premature failures - and, hence, lower values - while our values are higher than those previously reported, though not that substantially, considering the range reported in the review by Söderholm (2010): $1-4 \mathrm{MPa} \cdot \mathrm{m}^{1 / 2}$ and 1-2 MPa $\cdot \mathrm{m}^{1 / 2}$ for dentin and interface specimens, respectively (standard deviations often exceeding 25\%).

Despite the strongly expressed urge for an interfacial fracture toughness (iFT) approach at the 2009 Academy of Dental Materials meeting (Portland, OR), the technical complexity of fracture toughness testing probably discouraged researchers from producing new fracture toughness data. Triggered by this symposium, we first developed a macro-iFT test (De Munck et al. 2013; De Munck et al. 2015). Here, we introduced a miniiFT version, which appeared almost as feasible as common microtensile bond strength testing; it caused specimens to fail at the actual interface with lower variation (Pongprueksa et al. 2016). We therefore encourage other researchers to pick up this novel approach. Meanwhile, further validation was conducted in the framework of the PhD thesis of Dr. Pongprueksa (2016).

Bonding effectiveness can be measured in different waysin this case, through common bond strength testing but also through an iFT approach. We use bonding effectiveness as a compilation term for the perceived effectiveness of an adhesive to bond.

\section{Acknowledgments}

The authors received no financial support and declare no potential conflicts of interest with respect to the authorship and/or publication of this article.

\section{References}

De Munck J, Luehrs AK, Poitevin A, Van Ende A, Van Meerbeek B. 2013. Fracture toughness versus micro-tensile bond strength testing of adhesivedentin interfaces. Dent Mater. 29(6):635-644.

De Munck J, Poitevin A, Lührs AK, Pongprueksa P, Van Ende A, Van Landuyt KL, Van Meerbeek B. 2015. Interfacial fracture toughness of aged adhesive-dentin interfaces. Dent Mater. 31(4):462-472.

Pongprueksa P. 2016. Polymerization efficiency of dental adhesives. PhD dissertation, KU Leuven, Leuven, Belgium.

Pongprueksa P, De Munck J, Karunratanakul K, Barreto BC, Van Ende A, Senawongse P, Van Meerbeek B. 2016. Dentin bonding testing using a mini-interfacial fracture toughness approach. J Dent Res. 95(3):327-333.

Ruse ND. 2016. Letter to the editor: dentin bonding testing using a miniinterfacial fracture toughness approach. J Dent Res. In press. doi:10.1177/ 0022034516651054

Söderholm KJ. 2010. Review of the fracture toughness approach. Dent Mater. 2010. 26(2):e63-e77.

\footnotetext{
'KU Leuven (University of Leuven), Department of Oral Health Sciences, BIOMAT and University Hospitals Leuven, Dentistry, Leuven, Belgium

${ }^{2}$ Department of Operative Dentistry and Endodontics, Faculty of Dentistry, Mahidol University, Bangkok, Thailand

${ }^{3}$ National Metal and Materials Technology Center, National Science and Technology Development Agency, Pathumthani, Thailand

\section{Corresponding Author:}

B. Van Meerbeek, KU Leuven (University of Leuven), Department of Oral Health Sciences, BIOMAT, Kapucijnenvoer 7, Blok A-Box 700I, B-3000 Leuven, Belgium.
}

Email: bart.vanmeerbeek@kuleuven.be 